\title{
MICROBIAL PRODUCTS
}

\author{
VIII ${ }^{1)}$. AZINOTHRICIN, A NOVEL HEXADEPSIPEPTIDE ANTIBIOTIC
}

\author{
Hubert Maehr, Chao-min Liu, Norberto J. Palleroni, Joanne Smallheer, \\ Louis Todaro, Thomas H. Williams and John F. Blount
}

Chemical Division, Roche Research Center, Hoffmann-La Roche Inc. Nutley, New Jersey 07110, U.S.A.

(Received for publication September 3, 1985)

\begin{abstract}
Azinothricin was isolated from the culture filtrate of Streptomyces sp. X-14950 in crystalline form. It represents a new type of hexadepsipeptide antibiotic as it contains a 19-membered cyclodepsipeptide ring composed of six unusual amino acids and bearing a novel C21 side chain. Azinothricin was identified as $\left[\left(3 S, 4 S, 7 R\left(S^{*}\right), 10 S, 17 R, 20 S, 23 R\right)\left[2 S\left(2^{\prime} R^{*}, 5^{\prime} S^{*}\right.\right.\right.$, $\left.\left.6^{\prime} S^{*}\right) 3 S^{*}\right]$ ]- $\alpha$-ethyl-6 - (3-ethyl - 1,5 - dimethyl - 4-oxo-1,5-heptadienyl) - $N$ - $(1,8,14,15,18,21,27$ heptaaza-21 - hydroxy - 7-(1-hydroxyethyl)-2,6,9,16,19,22-hexaoxo-4-isopropyl-20 -(methoxymethyl)-17,18-dimethyl-5-oxatricyclo[21.4.0.0 ${ }^{10,15}$ heptacosan-3-yl)tetrahydro- $\alpha, 2$-dihydroxy-5methyl-2H-pyran-2-acetamide and is primarily active against Gram-positive microorganisms.
\end{abstract}

The culture filtrate of Streptomyces sp. X-14950 attracted our attention in view of its potent in vitro activity against Gram-positive bacteria. The active principle was isolated in crystalline form and identified as a novel cyclohexadepsipeptide antibiotic, termed azinothricin (1). The chemical structure of $\mathbf{1}$ incorporates erythro-3-hydroxy-L-leucine, D-threonine, L-piperazic acid, $N$-methyl-Dalanine, $\mathrm{N}$-hydroxy- $\mathrm{O}$-methyl-L-serine, and D-piperazic acid. These six unusual amino acids make up the 19-membered cyclodepsipeptide ring in which the erythro-3-hydroxyleucine moiety provides the hydroxyl group for the lactone linkage and the amino group for an amide bond to a $\mathrm{C} 21$ side chain. Due to the presence of $N$-hydroxy- $O$-methyl-L-serine, the 19 -membered lactone ring can also be regarded as a cyclic monohydroxamic acid. ${ }^{2)}$ The name of the antibiotic reflects the presence of the azino groups of the piperazic acid moieties which invite a comparison with the monamycin family of antibiotics. ${ }^{3)}$ In contrast to azinothricin, however, the monamycin antibiotics contain 18 -membered lactone rings composed of one 2-hydroxycarboxylic acid and only five amino acids. None of the amino acids present in monamycins occur in azinothricin with the exception of D-piperazic acid which is found in 9 of the 15 known monamycins. In spite of these chemical differences, the monamycins exhibit antimicrobial spectra similar to that of azinothricin and share toxic liabilities with the title compound which preclude its clinical use.

\section{Producing Culture}

The characteristics of growth and sporulation in various ISP media are summarized in Table 1. Media ISP 2, 4 and 5 support the best growth,

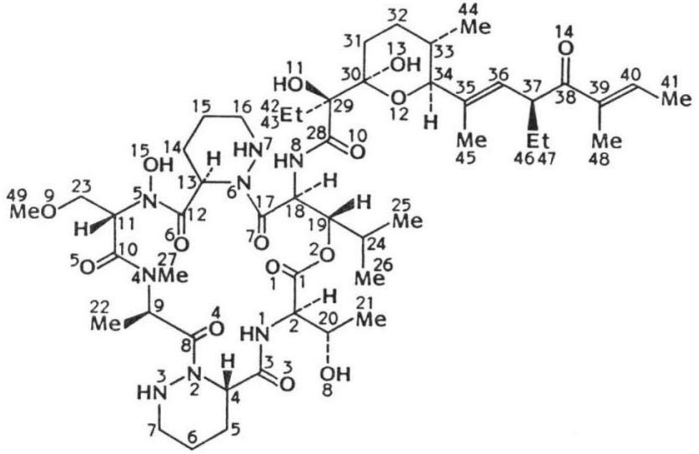

Azinothricin (1)

The numbering system shown here is arbitrary and serves only as an aid in NMR-spectral and crystallographic identifications. 
Table 1. Culture characteristics of Streptomyces sp. X-14950.

\begin{tabular}{|c|c|c|c|}
\hline Medium & $\begin{array}{l}\text { Amount of growth and } \\
\text { degree of sporulation }\end{array}$ & $\begin{array}{l}\text { Color of the } \\
\text { aerial mass* }\end{array}$ & $\begin{array}{l}\text { Color of the } \\
\text { reverse mycelium* }\end{array}$ \\
\hline $\begin{array}{l}\text { Yeast - malt extract } \\
\text { agar (ISP 2) }\end{array}$ & $\begin{array}{l}\text { Abundant growth; no fragmentation } \\
\text { of substrate mycelia. Sparse aerial } \\
\text { mycelium. No sporulation. }\end{array}$ & $\begin{array}{l}\text { Light yellow } \\
(1-1 / 2 \mathrm{fv}) \\
\text { mixed with } \\
\text { alabaster tint } \\
(13 \mathrm{ba})\end{array}$ & $\begin{array}{l}\text { Sunlight yellow } \\
(1-1 / 2 \text { ia })\end{array}$ \\
\hline $\begin{array}{l}\text { Oatmeal agar } \\
\text { (ISP 3) }\end{array}$ & $\begin{array}{l}\text { Fair growth, no fragmentation of } \\
\text { substrate mycelia. Light, even } \\
\text { sporulation. Flexibilis type. }\end{array}$ & White (a) & Pearl (2 ba) \\
\hline $\begin{array}{l}\text { Inorganic salts } \\
\text { agar }\end{array}$ & $\begin{array}{l}\text { Abundant growth; no fragmentation } \\
\text { of substrate mycelia. Dense mat of } \\
\text { sporulation. Rectus to flexibilis } \\
\text { type. }\end{array}$ & White (a) & $\begin{array}{l}\text { Light yellow } \\
(1-1 / 2 \text { ea })\end{array}$ \\
\hline $\begin{array}{l}\text { Glycerol - } \\
\text { asparagine agar } \\
\text { (ISP 5) }\end{array}$ & $\begin{array}{l}\text { Abundant growth; no fragmentation } \\
\text { of substrate mycelia. Dense mat of } \\
\text { sporulation. Rectus type. }\end{array}$ & $\begin{array}{l}\text { Alabaster tint } \\
(13 \mathrm{ba})\end{array}$ & Pearl (2 ba) \\
\hline
\end{tabular}

* Colors described according to the Color Harmony Manual, 4th Ed., Container Corp. of America, Chicago, 1958.

whereas sporulation is most abundant on ISP 4 and 5.

As indicated in Table 1 no fragmentation of the substrate mycelium has been observed in any of the agar media. Spore chains were found to correspond to the rectus-flexibilis type, with 20 or more spores per chain. The average width of the spores was $0.57 \mu \mathrm{m}$, and the length varied from 0.96 to $1.55 \mu \mathrm{m}$. The surface of the spores was smooth (Fig. 1).

Optimum growth temperature was determined to be $28^{\circ} \mathrm{C}$ with slightly less growth at $37^{\circ} \mathrm{C}$.

Fig. 1. Spore chains of Streptomyces sp. X-14950.

The fragility of the mature chains is evident. ISP 4, 14-day culture. Bar represents $5 \mu \mathrm{m}$. Spore dimensions: $0.95 \sim 1.55 \mu \mathrm{m} \times 0.55 \mu \mathrm{m}$.

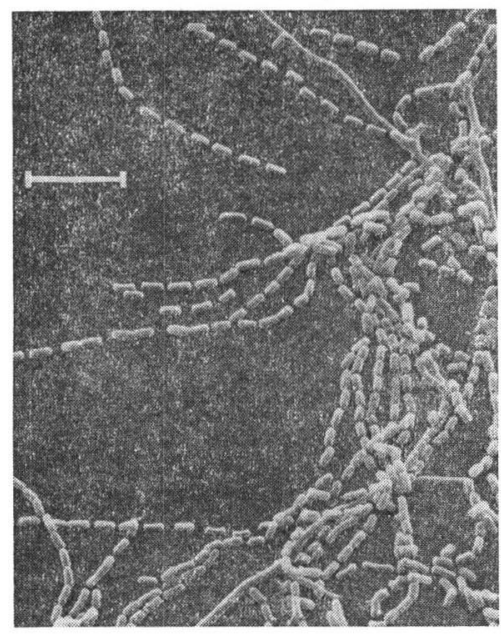

Glucose, arabinose, fructose, galactose, inositol, mannitol, xylose, salicin, and melibiose could serve as carbon sources, but the culture did not utilize rhamnose or sucrose, and the utilization of raffinose and lactose was doubtful. On Czapek-solution agar, growth was fair and sporulation was good.

The culture showed strong reduction of nitrate after 7 days, indicated by a dark-red color after addition of the reagents. Tolerance to $\mathrm{NaCl}$ was not determined because of poor growth in the test medium. The culture decomposed hypoxanthine, xanthine and urea, and hydrolyzed starch and casein. Esculin was not hydrolyzed and melanin was not produced on either ISP 6 or ISP 7 media.

Species X-14950 is sensitive to streptomycin as a $7-\mathrm{mm}$ disc containing $10 \mu \mathrm{g}$ of streptomycin gave a $13.5-\mathrm{mm}$ zone of inhibition.

Three species of Streptomyces described in the literature ${ }^{4)}$ resemble strain X-14950. These are $S$. badius, S. felleus, and S. sampsonii. They belong to the rectiflexibilis type, and they have smooth 
spores. None of the cultures produces melanin or have distinctive reverse pigments. The carbon utilization pattern of these cultures is essentially the same as that of X-14950. In fact, the published information available on these three species is insufficient not only for a differentiation from X-14950, but also for a clear separation from each other, so that a certain assignment of species X-14950 to any of the above-mentioned strains is not feasible.

\section{Fermentation and Isolation}

Streptomyces sp. X-14950 was cultured and maintained on a starch - casein agar slant of the following composition ( $\mathrm{g} /$ liter distilled water); soluble starch 10 , casein $1, \mathrm{~K}_{2} \mathrm{HPO}_{4} 0.5, \mathrm{MgSO}_{4} 0.5$, and agar 20. The $\mathrm{pH}$ was adjusted to 7.4 with sodium hydroxide prior to autoclaving. The agar slant was inoculated with the culture and incubated at $28^{\circ} \mathrm{C}$ for $7 \sim 14$ days. A piece of such an agar slant, containing spores and mycelium, served as inoculum for $100 \mathrm{ml}$ of a medium (500-ml Erlenmeyer flask) with the following composition ( $\mathrm{g} /$ liter distilled water); tomato pomace 5 , distillers solubles 5 , OM peptone 5, debittered dried yeast 5, Eclipse $\mathrm{N}$ starch $20, \mathrm{~K}_{2} \mathrm{HPO}_{4} 1, \mathrm{CaCO}_{3} 1$, and $\mathrm{CoCl}_{2} \cdot 6 \mathrm{H}_{2} \mathrm{O}$ 0.000238 . The medium was adjusted to $\mathrm{pH} 7$, autoclaved, inoculated and incubated at $28^{\circ} \mathrm{C}$ for 2 days on a rotary shaker at $250 \mathrm{rpm}$. Portions of the resulting culture $(20 \mathrm{ml})$ were used to inoculate 6-liter Erlenmeyer flasks containing 2 liters of medium, with the same composition each. Four liters of the resulting broth, obtained after incubation for 2 days at $28^{\circ} \mathrm{C}$ and $250 \mathrm{rpm}$, served as inoculum for a 230-liter fermentation employing the same medium as described above with the exception that tap water was used and that antifoam SAG 4130 (Union Carbide, $0.1 \mathrm{~g} /$ liter) was added. The inoculated fermentor was aerated at a rate of $0.085 \mathrm{~m}^{3} /$ minute and stirred at an impeller speed of 280 rpm for 118 hours at $28^{\circ} \mathrm{C}$.

The whole broth was extracted with ethyl acetate (200 liters), the extract was evaporated and the residue triturated with diethyl ether. The ether-insoluble residue was discarded and the filtrate evaporated. The resulting residue was chromatographed on silica gel with a dichloromethane and dichloromethane-ethanol (9:1) gradient. The major antibacterial fraction (Staphylococcus aureus as test organism) was evaporated and rechromatographed as described above. The syrup obtained upon evaporation was taken up in methanol and allowed to crystallize. The pure antibiotic was obtained after one recrystallization from methanol and several crystallizations from acetone. Thus $1.4 \mathrm{~g}$ of $\mathbf{1}$ was obtained, and an additional $2 \mathrm{~g}$ of material could be recovered by chromatography of the evapo-

Fig. 2. IR spectrum of azinothricin in $\mathrm{KBr}$.

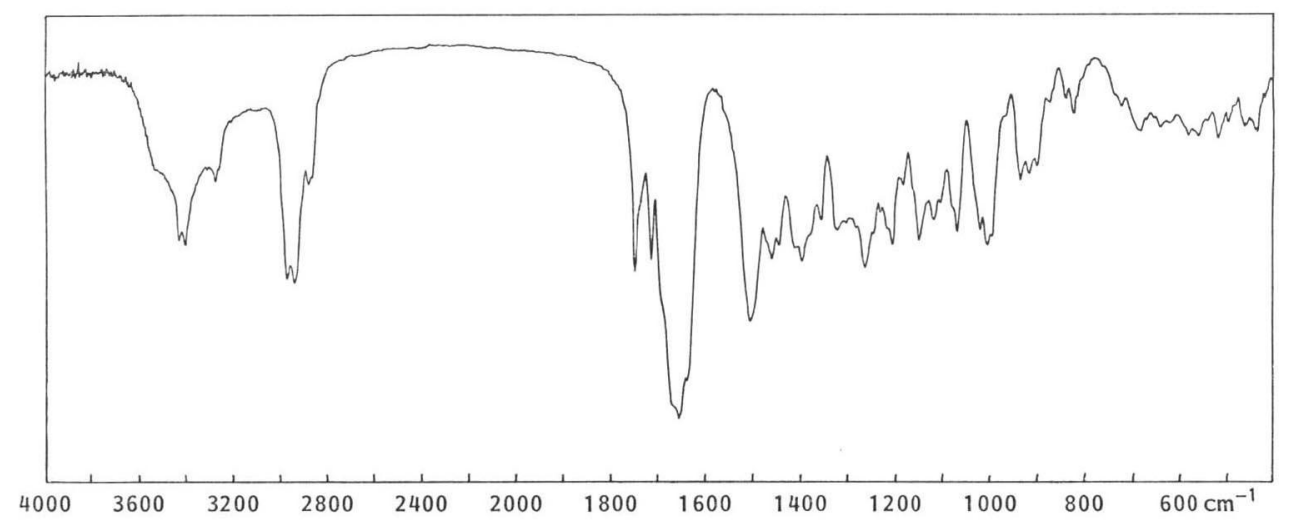


rated mother liquors on silica gel with a dichloromethane and ethyl acetate gradient followed by crystallization from acetone.

\section{Chemical Characterization and Structure Determination}

Azinothricin, recrystallized from acetone as an acetone monosolvate, exhibited $\mathrm{mp}>188^{\circ} \mathrm{C}$ (dec); $[\alpha]_{D}^{25}+117.65^{\circ}\left(c 0.6, \mathrm{CHCl}_{3}\right.$ ); Rf 0.75 (silica gel plates) (dichloromethane - hexane - ethanol, 8: 2: 1); UV $\lambda_{\max }$ (dioxane) $225 \mathrm{~nm}(\mathrm{sh}, \varepsilon 18,920)$; IR $(\mathrm{KBr}) 3500(\mathrm{OH}), 3425,3400(\mathrm{NH}), 1745$ (lactone $\mathrm{C}=\mathrm{O}$ ) $\mathrm{cm}^{-1}$ (Fig. 2); $200 \mathrm{MHz}{ }^{1} \mathrm{H}$ NMR $\delta 0.71,0.74,0.82$ (3d, 3 each, $J=7 \mathrm{~Hz}, \mathrm{H} 25,26,44$ ), 0.84, 0.86 (2t, 3 each, $J=7 \mathrm{~Hz}, \mathrm{H} 43,47$ ), 1.07 (d, 3, $J=7 \mathrm{~Hz}, \mathrm{H} 21$ ), 1.28 (d, 3, $J=7 \mathrm{~Hz}, \mathrm{H} 22$ ), 1.35 2.35 (m, H5, 6 ,14, 15, 31, 32, 42, 46), 1.60 (s, 3, H45), 1.78 (s, 3, H48), 1.87 (d, 3, J=7 Hz, H41), 2.01 (m, 1, CH), $2.50 \sim 3.40$ (m, H7, 16), 2.62 (m, 1, CH), 2.97 (s, 1, OH), 3.08 (s, 3, H27), 3.38 (s, 3, H49), 3.76, $3.87\left(\mathrm{AB}, 2, J_{\text {gem }}=11 \mathrm{~Hz}, J_{\text {vic }}=6.5\right.$ and $\left.7.5 \mathrm{~Hz}, \mathrm{H} 23\right), 3.88(\mathrm{~m}, 1, \mathrm{NH}), 3.96(\mathrm{~m}, 1, \mathrm{H} 37), 4.00,4.53$ (2d, 2, $J=9 \mathrm{~Hz}, 2 \mathrm{CH}), 4.34$ (s, 1, OH), 4.43 (d, 1, J=11 Hz, NH), 4.80 (q, 1, J=7 Hz, H20), 4.92, 4.94, 5.20 (3m, 1 each, $3 \mathrm{CH}), 5.31(\mathrm{t}, 1, J=7 \mathrm{~Hz}, \mathrm{H} 11), 5.40$ (d, $1, J=11 \mathrm{~Hz}, \mathrm{CH}), 5.55$ (d, $1, J=9$ $\mathrm{Hz}, \mathrm{CH}), 6.12$ (q, 1, $J=7 \mathrm{~Hz}, \mathrm{H9}$ ), 6.22 (d, 1, $J=9 \mathrm{~Hz}, \mathrm{~N} 1-\mathrm{H}), 6.25$ (s, 1, OH), 6.73 (q, 1, $J=7 \mathrm{~Hz}$, $\mathrm{H} 40), 8.25$ (d, 1, J=11 Hz, N8-H), $9.96(\mathrm{~s}, 1, \mathrm{O} 15-\mathrm{H})$. The multiplicity of the bands was confirmed

Fig. 3. NMR spectra of azinothricin in $\mathrm{CDCl}_{3}$ (top: $200 \mathrm{MHz}$ NMR spectrum; center: $50.3 \mathrm{MHz}$ spectrum, negative $\mathrm{CH}_{2}$, positive $\mathrm{CH}, \mathrm{CH}_{3}$; bottom: $50.3 \mathrm{MHz}$ spectrum, ${ }^{1} \mathrm{H}$ decoupled).
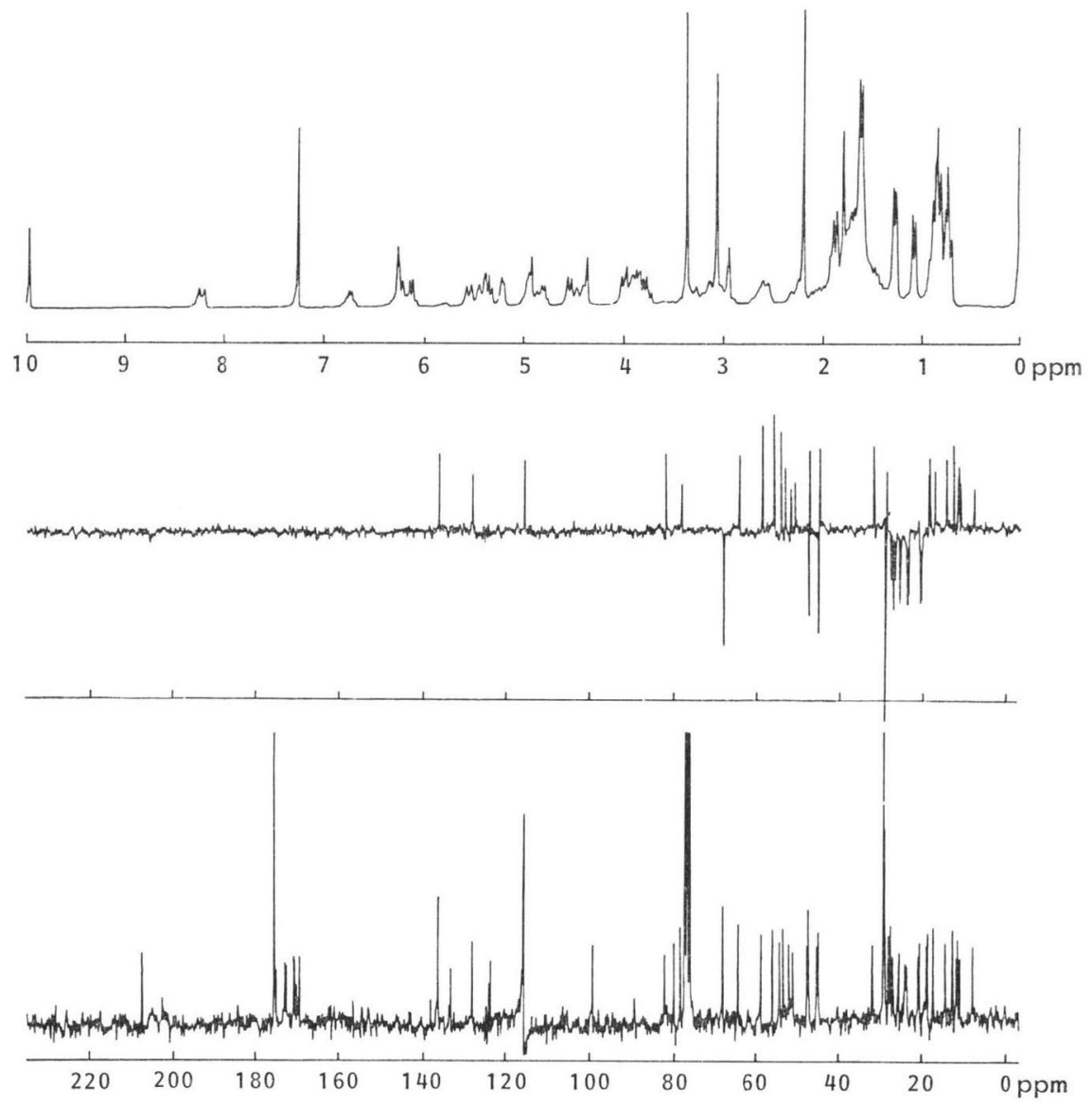
Fig. 4. Stereoscopic drawings of the major (top) and minor rotamer (bottom) of azinothricin.
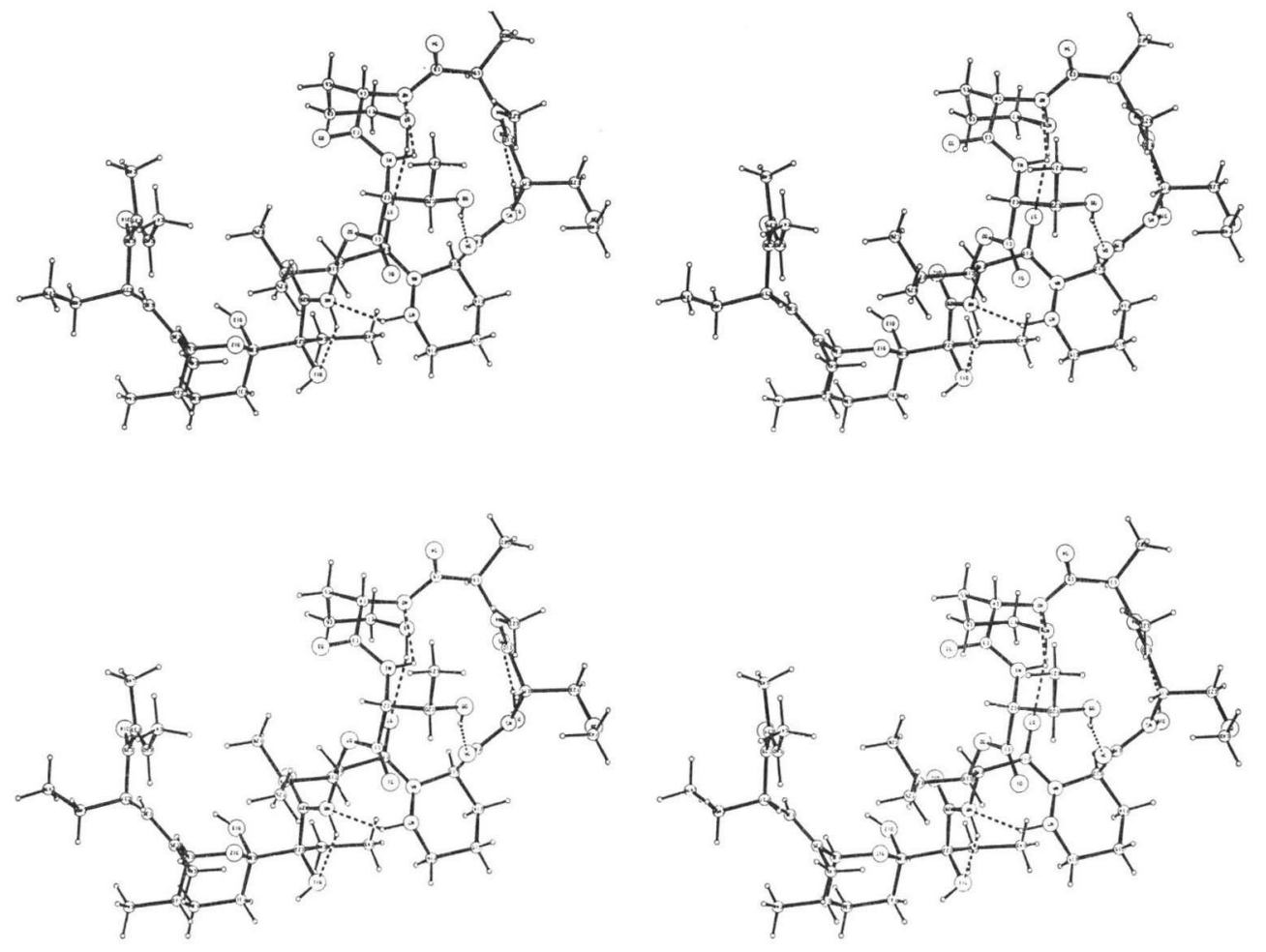

Fig. 5. Stereoscopic drawings of the major (top) and minor rotamer (bottom) of azinothricin.
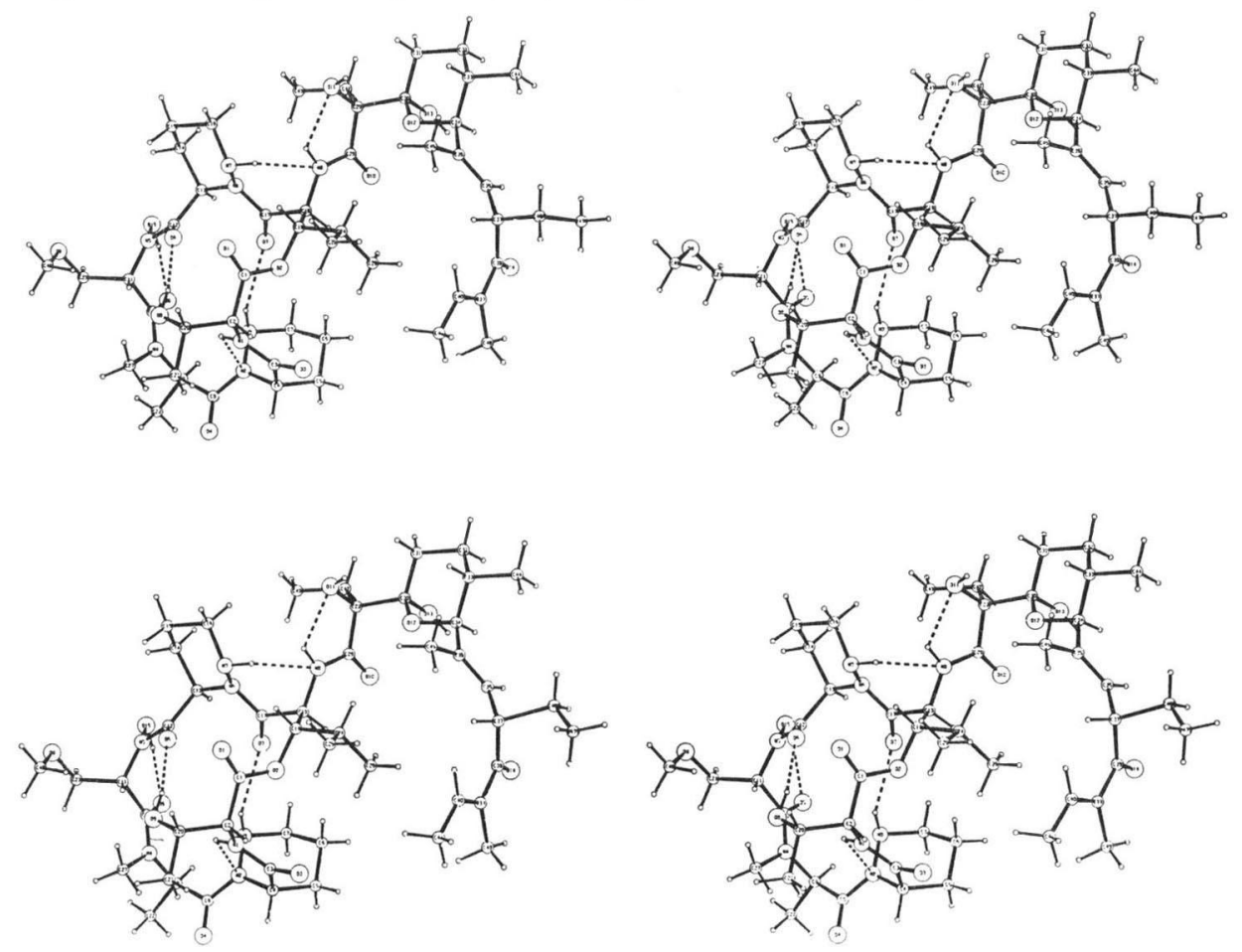
by a $100 \mathrm{MHz}{ }^{1} \mathrm{H}$ NMR spectrum.

The corresponding $50.3 \mathrm{MHz}^{13} \mathrm{C}$ NMR spectrum showed $10 C$-methyl groups at 8.33, 11.41, 11.95, $12.26,13.22,14.79,14.96,17.77,18.95,19.29 ; 8 \mathrm{CH}_{2}$ groups at 21.19, 21.38, 24.16, 24.46, 26.04, 27.34, $27.83,28.38 ; 2 \mathrm{NCH}_{2}$ groups at 45.71 and $48.05 ; \mathrm{OCH}_{2}(\mathrm{C} 23)$ at $68.57 ; \mathrm{NCH}_{3}\left(\mathrm{C}_{27}\right), \mathrm{OCH}_{3}\left(\mathrm{C}_{9}\right)$ and $12 \mathrm{CH}$ groups at 29.43, 29.70, 32.45, 45.27, 47.73, 51.33, 52.43, 53.85, 54.70, 56.28, 59.25, 64.85, 78.71, 82.55; CH-36 and 40 at 128.56, 136.79; C29 at 80.17; C30 at 99.67; C35 and/or C39 at $133.80 ;$ lactone carbonyl and $6 \mathrm{~N}$-carbonyl at 169.11, 170.35, 170.92, 171.09, 172.89, 173.17, 175.32; and C38 carbonyl at 207.44. The ${ }^{1} \mathrm{H}$ and ${ }^{13} \mathrm{C}$ NMR spectra, including a plot representing a refocused INEPT experiment set for $\mathrm{CH}_{2}$ carbons are shown in Fig. 3.

Anal Calcd for $\mathrm{C}_{48} \mathrm{H}_{80} \mathrm{~N}_{8} \mathrm{O}_{15} \cdot \mathrm{C}_{3} \mathrm{H}_{6} \mathrm{O}$ : C 57.76, $\mathrm{H} 8.20, \mathrm{~N} 10.36$. Found: C 57.91, H 7.86, N 10.31.

FAB mass spectrometry suggested a molecular weight of 1,002 , but the peak $\mathrm{m} / z 1,002$ was subsequently interpreted as $\mathrm{M}-\mathrm{H}_{2} \mathrm{O}$ in view of a crystallographic analysis indicating a molecular weight of 1,020 .

The crystal selected for the Roentgen diffraction data was approximately $0.14 \times 0.20 \times 0.7 \mathrm{~mm}$ (Hilger-Watts diffractometer, Ni-filtered $\operatorname{CuK} \alpha$ radiation, $\theta-2 \theta$ scans, pulse-height discrimination, data not corrected for absorption). Of the 4,537 independent reflections for $\theta<57^{\circ}, 2,879$ were considered to be observed $[\mathrm{I}>2.5 \sigma(\mathrm{I})]$.

The acetone monosolvate is orthorhombic, space group $\mathrm{P} 2_{1} 2_{1} 2_{1}, a=9.778(2), b=20.700(4), c=$

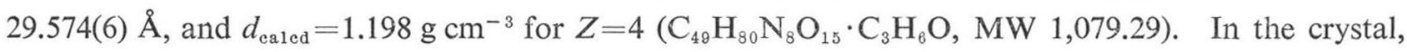
the ethyl group attached to C37 was disordered. This disorder was described by resolving the ethyl group into two moieties. Thus, for approximately $60 \%$ of the molecules in the crystal, the ethyl moiety was oriented as shown in Fig. 4 and for the remaining 40\%, it had the orientation as in Fig. 5. The hydroxyl group $\mathrm{O}(11) \mathrm{H}$ was weakly hydrogen bonded to $\mathrm{O} 50$ of the acetone molecule. The instability of this hydrogen bond is indicated by the tendency of the acetone molecules to escape readily from the crystal. For this reason, the crystal was coated with epoxy cement to minimize acetone evolution during data collection and to preserve crystallinity.

The structure was solved by a multiple-solution procedure ${ }^{5)}$ and was refined by block-diagonal least squares in which the matrix was partitioned into three blocks. In the final refinement, the nonhydrogen atoms were refined anisotropically, except for the carbon atoms of the two resolved ethyl groups, which were refined isotropically. The occupancy factors of the atoms of the ethyl moiety in the major rotamer were adjusted to 0.6 , and to 0.4 for those in the minor rotamer, so as to obtain approximately equal isotropic thermal parameters for the corresponding atoms in the two ethyl groups. The hydrogen atoms were included in the structure factor calculations but their parameters were not refined. The final discrepancy indices are $\mathrm{R}=0.055$ and $\mathrm{w}=0.048$ for the 2,879 observed reflections.

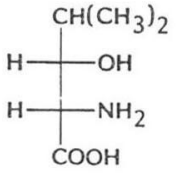

2

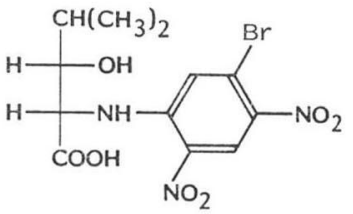

3
The final difference map has no peaks greater than $\pm 0.2 \mathrm{e} \AA^{-3}$.

The assignment of the absolute configuration to azinothricin is based on the determination of the L-configuration of erythro-3-hydroxyleucine (2), isolated from the antibiotic hydrolysate and also known as a constituent of the antibiotic telomycin. ${ }^{6,7)}$ 
Azinothricin $(1 \mathrm{~g})$ was hydrolyzed in a sealed tube with $6 \mathrm{~N} \mathrm{HCl}(15 \mathrm{ml})$ at $100^{\circ} \mathrm{C}$ for 18 hours. The filtered hydrolysate was evaporated, the residue dissolved in water and the solution chromatographed on a column of Dowex 50X-8, $25 \times 680 \mathrm{~mm}, 200 \sim 400$ mesh, with a pH 3.44 citrate buffer as mobile phase $(19.6 \mathrm{~g}$ trisodium citrate dihydrate and $11.7 \mathrm{ml}$ concd $\mathrm{HCl}$ per liter, $400 \mathrm{ml}$ ). Erythro3-hydroxyleucine was eluted with a $\mathrm{pH} 4.12$ buffer (19.6 g trisodium citrate dihydrate, $11.7 \mathrm{~g} \mathrm{NaCl}$ and $8.34 \mathrm{ml}$ concd $\mathrm{HCl}$ per liter, $400 \mathrm{ml})$. Desalting on Dowex $50\left(\mathrm{H}^{+}\right)$furnished the pure amino acid as amorphous residue (50 mg), Rf 0.30 (TLC, E. Merck, silica gel 60, 1- $\mathrm{BuOH}-\mathrm{AcOH}-\mathrm{H}_{2} \mathrm{O}, 4: 1: 1$ ), $100 \mathrm{MHz}{ }^{1} \mathrm{H} \mathrm{NMR}\left(\mathrm{D}_{2} \mathrm{O}\right) \delta 1.46\left(\mathrm{~d}, 6, J=7 \mathrm{~Hz}, \mathrm{Me}_{2} \mathrm{C}\right), 2.40(\mathrm{~m}, 1, \mathrm{H} 4), 4.03\left(\mathrm{dd}, 1, J_{2,3}=4\right.$ and $J_{3,4}=$ $9 \mathrm{~Hz}, \mathrm{H} 3), 4.41$ (d, 1, $\left.J_{2,3}=4 \mathrm{~Hz}, \mathrm{H} 2\right)$.

Anal Calcd for $\mathrm{C}_{6} \mathrm{H}_{13} \mathrm{NO}_{3}$ : C 48.97, $\mathrm{H}$ 8.90, N 9.52.

Found: $\quad$ C $48.37, \mathrm{H} 8.98, \mathrm{~N} 9.54$.

A solution of 1-bromo-3-fluoro-4,6-dinitrobenzene ${ }^{8)}(130 \mathrm{mg})$ in ethanol $(2 \mathrm{ml})$ was added to a solution of the amino acid $(25 \mathrm{mg})$ in water $(1 \mathrm{ml})$ containing sodium hydrogen carbonate $(84 \mathrm{mg})$. The mixture was agitated in the dark overnight, evaporated and the residue was partitioned between water and ether. The aqueous phase was extracted again with ether, acidified $(1 \mathrm{M} \mathrm{HCl})$ and extracted repeatedly with ether. The combined extracts from the acidified solution were washed with brine and evaporated, the residue was chromatographed on silicic acid with chloroform as mobile phase. Chloroform containing $2 \%$ acetone eluted the major yellow band. Evaporation of the pooled fractions gave 3 which was crystallized from acetone - cyclohexane as yellow plates, Rf 0.64 $\left(\mathrm{CHCl}_{3}-\mathrm{MeOH}-\mathrm{AcOH}, 16: 4: 1\right), \mathrm{mp} 116 \sim 117^{\circ} \mathrm{C}, 100 \mathrm{MHz}{ }^{1} \mathrm{H}$ NMR $\left(\mathrm{CDCl}_{3}-\mathrm{DMSO}_{6}, 20: 1\right) \delta$ 1.04, 1.11 (2d, 3 each, $J=5 \mathrm{~Hz}$ each, $\mathrm{Me}_{2} \mathrm{C}$ ), 2.02 (m, 1, H4), 2.16 (s, 4, 2/3 $\mathrm{Me}_{2} \mathrm{CO}$ ), 3.64 (dd, 1, $J_{2,3}=$ 3.5 and $\left.J_{3,4}=8 \mathrm{~Hz}, \mathrm{H} 3\right), 4.45\left(\mathrm{dd}, 1, J_{2,3}=3.5\right.$ and $\left.J_{2, \mathrm{NH}}=8 \mathrm{~Hz}, \mathrm{H} 2\right), 6.30$ (br, 2, COOH and OH), 7.29 (s, 1, H2 of aromatic), 8.97 (s, 1, H5 of aromatic), 9.12 (d, 1, $J_{2, \mathrm{NH}}=8 \mathrm{~Hz}, \mathrm{NH}$ ). Mass spectrum $m / z$ (relative intensity) $392(\mathrm{M}+\mathrm{H},<1), 373\left(\mathrm{M}-\mathrm{H}_{2} \mathrm{O},<1\right), 358\left(\mathrm{M}-\mathrm{H}_{2} \mathrm{O}-\mathrm{Me},<1\right), 319(\mathrm{M}-$ $\left.\mathrm{Me}_{2} \mathrm{CH}(\mathrm{CHOH})+\mathrm{H}, 5\right), 301$ (2).

Anal Caled for $\mathrm{C}_{12} \mathrm{H}_{14} \mathrm{BrN}_{3} \mathrm{O}_{7} \cdot \mathrm{C}_{3} \mathrm{H}_{6} \mathrm{O}$ : C $40.02, \mathrm{H} 4.48, \mathrm{~N} 9.33$. Found:

C $40.25, \mathrm{H} 4.40, \mathrm{~N} 9.27$.

$[\alpha]_{\mathrm{D}}^{25}-39.92^{\circ}(c 0.76$, EtOAc).

Roentgen diffraction studies (vide supra) were based on a diamond-shaped plate approximately $0.1 \times 0.4 \times 0.4 \mathrm{~mm}$ in size. Of the 2,210 accessible reflections with $\theta<76^{\circ}$, the intensities of 2,136 were significantly greater than background $[\mathrm{I}>2.5 \sigma(\mathrm{I})]$ and were used in the analysis. The crystal was of space group $\mathrm{P}_{1}, a=15.878(8), b=6.513(2), c=9.881(3) \AA, \beta=104.52(3)^{\circ}$, and $d_{\text {caled }}=1.511 \mathrm{~g} \mathrm{~cm}^{-3}$ for $Z=2\left(\mathrm{C}_{12} \mathrm{H}_{14} \mathrm{BrN}_{3} \mathrm{O}_{7} \cdot \mathrm{C}_{3} \mathrm{H}_{6} \mathrm{O}\right.$, MW 450.25).

The structure (Fig. 6) was solved by standard Patterson and Fourier techniques. Full-matrix least squares were used for all refinements. The imaginary part of the anomalous dispersion correction $\left(\Delta \mathrm{f}^{\prime \prime}\right)$ was set to zero during the preliminary refinement of the structure. At the conclusion of this refinement (all atoms anisotropic) a difference Fourier was calculated. Peaks were found on this map at reasonable positions for almost all hydrogen atoms except those of the acetone molecule. The positions of all hydrogen atoms were calculated. These hydrogens were included in all subsequent calculations but their parameters were not refined. The final unweighted discrepancy index is $\mathbf{R}=$ 0.033 for the 2,136 observed reflections.

To establish the absolute configuration, two separate refinements were made following the conclusion of the preliminary refinement in which $\Delta \mathrm{f}^{\prime \prime}$ had been ignored. In one refinement the correct 
Fig. 6. Stereoscopic drawing of $\mathbf{3}$ showing its conformation and absolute configuration.

The acetone molecule has been omitted. The thermal ellipsoids are scaled to the $50 \%$ probability level and the hydrogen atoms are shown as spheres of a fixed, arbitrary size.
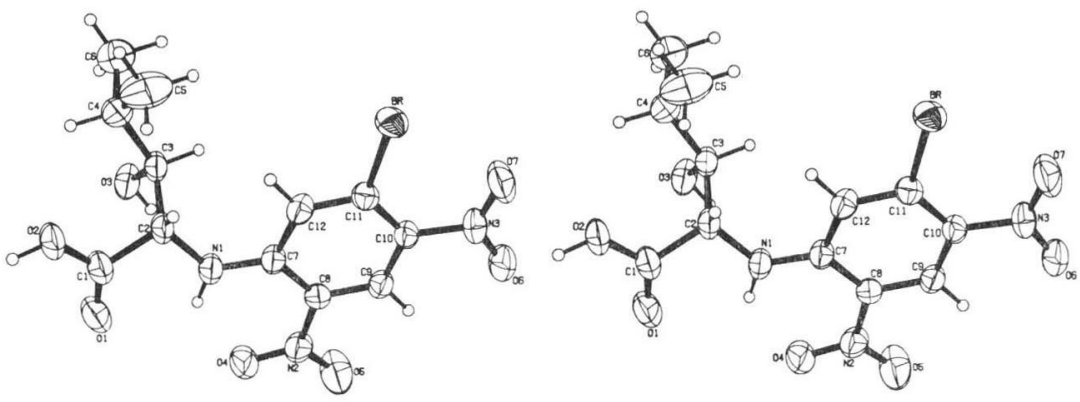

value of $\Delta \mathrm{f}^{\prime \prime}$ was used and in the other the sign of $\Delta \mathrm{f}^{\prime \prime}$ was reversed (equivalent to refining the an tipode). The final weighted $\mathrm{R}$ values for the two refinements were 0.0553 and 0.0574 . Thus, according to the test described by HAmiLton, ${ }^{92}$ the absolute configuration can be taken as the one corresponding to the lower R value at a significance level exceeding 0.995 .

This determination of the absolute configuration was corroborated by the classical method of BiJvOET $^{10)}$. For each reflection $h k l$ for which $\mathrm{F}_{\mathrm{o}}(h k l)>20 \mathrm{e}$, structure factors were calculated for the reflection and the related reflection $h \bar{k} l$. (In the space group $\mathrm{P} 2_{1}$ the reflections $h k l$ and $h \bar{k} l$ are, in the absence of the anomalous dispersion, equal. When one takes into account the anomalous dispersion correction, however, they no longer are equal). Of the reflections with $F_{0}>20$ e, there were 26 pairs for which the difference in the calculated intensities, $\Delta \mathrm{I}_{\mathrm{c}}(h k l)=\mathrm{I}_{\mathrm{c}}(h k l)-\mathrm{I}_{\mathrm{c}}(h \bar{k} l)$, exceeded $5 \%$ of the average intensity of the pair. For each of these 26 reflection pairs, the intensities of four symmetry equivalent reflections were measured. Taking into account the chirality of the molecule and the anomalous dispersion, each set of four reflections can be divided into two sets of two with $\mathrm{I}(h k l)=$ $\mathrm{I}(\bar{h} k \bar{l})$ and $\mathrm{I}(h \bar{k} l)=\mathrm{I}(\bar{h} \bar{k} \bar{l})$ but with $\mathrm{I}(h k l) \neq \mathrm{I}(h \bar{k} l)$. After measuring the intensities of these selected reflections the differences in the observed intensities $\Delta \mathrm{I}_{0}(h k l)=\mathrm{I}_{0}(h k l)-\mathrm{I}_{0}(h \bar{k} l)$ were compared with the calculated differences (based on the absolute configuration previously assigned). In 22 of the 26 cases the signs of $\Delta \mathrm{I}_{\mathrm{o}}(h k l)$ and $\Delta \mathrm{I}_{\mathrm{c}}(h k l)$ were the same and in the other four cases the magnitude of $\Delta \mathrm{I}_{\mathrm{o}}(h k l)$ was too small for the sign to be considered significant. Thus, the classical method of BIJVOET $^{10)}$ fully confirmed the absolute configuration as determined by the method of HAMILTON.

The final atomic parameters and the anisotropic thermal parameters have been deposited at the Crystallographic Data Center. Since the relative configuration of $\mathbf{1}$ was established on the basis of its crystallographic analysis, the absolute configuration was now defined as well and is reflected in $\mathbf{1}$ by the use of topographic stereodescriptors. ${ }^{11)}$

\section{Biological Properties}

Azinothricin exhibited $\mathrm{LD}_{50}$ values in mice of 10 (intravenous), 3.2 (intraperitoneal), 420 (subcutaneous) and $>500$ (oral route) $\mathrm{mg} / \mathrm{kg}$. MIC values as determined by the broth micro-dilution method ranged from $<0.008$ to $0.016 \mu \mathrm{g} / \mathrm{ml}$ for 31 strains of Staphylococcus aureus and were 0.063 $\mu \mathrm{g} / \mathrm{ml}$ for 16 strains of Enterococcus faecalis, $0.016 \mu \mathrm{g} / \mathrm{ml}$ for 2 strains of Streptococcus pyogenes, and $<0.008 \mu \mathrm{g} / \mathrm{ml}$ for 2 strains of Streptococcus pneumoniae. Azinothricin was also active against the two anaerobes Clostridium histolyticum and Clostridium septicum with MIC values of $0.001 \mu \mathrm{g} / \mathrm{ml}$ 
each but was much less active against Gram-negative bacteria and fungi.

\section{Acknowledgment}

We thank Dr. G. Beskid for biological evaluations, Mr. G. F. Higgins, Jr. for technical assistance in the culture description, and Dr. P. A. Miller for his support and interest in this study.

\section{References}

1) Blount, J. F.; D. N. Greeley, H. Maehr, A. Perrotta, R. G. Pitcher, L. Todaro \& T. H. Williams: Microbial products. VII. The relative configuration of actinomycete metabolite X-14881D. J. Antibiotics 38: $1270 \sim 1272,1985$

2) MAEHR, H.: Antibiotics and other naturally occurring hydroxamic acids and hydroxamates. Pure Appl. Chem. 28: 603 636, 1971

3) Hassall, C. H.; R. B. Mortow, Y. Ogihara \& D. A. S. Phillips: Amino-acids and peptides. XII. The molecular structures of the monamycins, cyclodepsipeptide antibiotics. J. Chem. Soc. (C) 1971: $526 \sim 532,1971$

4) Buchanan, R. E. \& N. E. Gibbons (Eds.): Bergey's Manual of Determinative Bacteriology. 8th Ed., pp. 794 801, The Williams \& Wilkins Co., Baltimore, 1974

5) Germain, G.; P. Main \& M. M. Woolfson: Application of phase relationships to complex structures: The optimum use of phase relationships. Acta Cryst. A27: 368 376, 1971

6) Sheehan, J. C.; D. Mania, S. Nakamura, J. A. Stock \& K. Maeda: The structure of telomycin. J. Am. Chem. Soc. 90: 462 470, 1968

7) Sheehan, J. C.; K. Maeda, A. K. Sen \& J. A. Stock: The isolation, characterization and synthesis of erythro-3-hydroxy-L-leucine, a new amino acid from the antibiotic telomycin. J. Am. Chem. Soc. 84: $1303 \sim 1305,1962$

8) Maehr, H.; J. F. Blount, M. Leach \& A. Stempel: Antibiotic X-5108. VII. Absolute stereochemistry of 8-amino-3-methoxy-2,4-dimethyl-4,6-octadienal, a compound derived from antibiotic X-5108 and mocimycin. Helv. Chim. Acta 57: 936 940, 1974

9) Hamilton, W. C.: Significance tests on the crystallographic R factor. Acta Cryst. 18: 502 510, 1965

10) Bijvoet, J. M.; Am. F. Peerdeman, A. J. van Bommel: Determination of the absolute configuration of optically active compounds by means of X-rays. Nature 168: 271 272, 1951

11) MaeHr, H.: A proposed new convention for graphic presentation of molecular geometry and topography. J. Chem. Ed. 62: 114 120, 1985 